This item was submitted to Loughborough's Research Repository by the author.

Items in Figshare are protected by copyright, with all rights reserved, unless otherwise indicated.

\title{
Recovery of excreted $n$-butanol from genetically engineered cyanobacteria cultures: Process modelling to quantify energy and economic costs of different separation technologies
}

\section{PLEASE CITE THE PUBLISHED VERSION}

https://doi.org/10.1016/j.algal.2018.11.008

\section{PUBLISHER}

(C) Elsevier

\section{VERSION}

AM (Accepted Manuscript)

\section{PUBLISHER STATEMENT}

This paper was accepted for publication in the journal Algal Research and the definitive published version is available at https://doi.org/10.1016/j.algal.2018.11.008.

\section{LICENCE}

CC BY-NC-ND 4.0

\section{REPOSITORY RECORD}

Wagner, Jonathan, Daniel Lee-Lane, Mark Monaghan, Mahdi Sharifzadeh, and Klaus Hellgardt. 2018.

"Recovery of Excreted N-butanol from Genetically Engineered Cyanobacteria Cultures: Process Modelling to Quantify Energy and Economic Costs of Different Separation Technologies". figshare.

https://hdl.handle.net/2134/36303. 


\section{Recovery of excreted $n$-butanol from genetically engineered cyanobacteria cultures: Process modelling to quantify energy and economic costs of different separation technologies}

Jonathan L. Wagner, ${ }^{\text {a,b }}$ Daniel Lee-Lane, ${ }^{a}$ Mark Monaghan, ${ }^{a}$ Mahdi Sharifzadeh, ${ }^{a}$ Klaus Hellgardt ${ }^{\mathrm{a}}$

${ }^{a}$ Department of Chemical Engineering, Imperial College London, South Kensington, London, United Kingdom, SW7 2AZ

${ }^{b}$ Department of Chemical Engineering, Loughborough University, Loughborough, United Kingdom, LE11 3TU

\section{Abstract}

The photoautotrophic production of excreted biofuels from genetically engineered cyanobacteria and microalgae represents a new and promising alternative to conventional algal fuel technologies. $\mathrm{N}$-butanol is a particularly promising fuel product, as it can be directly used in petroleum engines, and has been successfully expressed in species of Synechococcus elongates 7942 and Synechocystis sp. PCC 6803. However, the high energy requirements of recovering butanol from dilute mixtures can easily outweigh the energy content of the fuel and must be carefully assessed and optimized. Consequently, the recovery of butanol was modelled using four of the most promising butanol separation technologies (distillation, gas stripping, pervaporation and ionic liquid extraction) to calculate the minimum butanol culture concentrations required to render the process energy-positive. With a breakeven concentration of only $3.7 \mathrm{~g} \mathrm{~L}^{-1}$, ionic liquid extraction proved much more efficient than the distillation base-case scenario $\left(9.3 \mathrm{~g} \mathrm{~L}^{-1}\right)$, whilst neither pervaporation $\left(10.3 \mathrm{~g} \mathrm{~L}^{-1}\right)$ nor gas stripping $\left(16.9 \mathrm{~g} \mathrm{~L}^{-1}\right)$ could compete on an energy basis with distillation. Despite this, due to the high costs of the ionic liquid solvent, the lowest capital costs are obtained for distillation 
(pilot plant scale, butanol culture concentrations of $10 \mathrm{~g} \mathrm{~L}^{-1}$ ), whilst pervaporation carries the lowest utility costs, as a result of its low electrical energy demand. Although currently achieved maximum $n$-butanol culture concentrations are significantly below the calculated break-even values for all four technologies, the present work provides an important threshold for future strain development. Moreover, the recovery of side-products from purged biomass could help to reduce the costs associated with biofuel production.

\section{Keywords}

Cyanobacteria, excreted biofuels, n-butanol production, process modelling, energy analysis

\section{Introduction}

Driven by concerns about climate change and energy security, the last two decades have seen an explosion in the global production of biofuels to substitute conventional, petroleumbased transportation fuels. Amongst these, bioethanol is by far the most widely used biofuel, as it can be easily produced from the fermentation of a wide range of biomass resources. Nevertheless, as a result of its high oxygen content, high hygroscopicity and low carbon chain length, the fuel properties of ethanol are far from ideal[1], limiting maximum blend concentrations in conventional petroleum combustion engines to $10 \mathrm{vol} \%$ [2][3].

Consequently, research interest has increasingly shifted to longer chain alcohols, particularly $n$-butanol, which can be produced via the ABE (Acetone Butanol Ethanol) fermentation process, using Clostridium acetobutylicum [4]. Unlike ethanol, butanol is not hydrogroscopic, is less corrosive and has a higher energy content of $29.2 \mathrm{MJ} \mathrm{L}^{-1}$, compared to $21.2 \mathrm{MJ} \mathrm{L}^{-1}$, which means it can be used either in pure or blended form, without engine modification [1]. Since the early 2000s, the process has been applied to a wide range of feedstocks, including sugars and starches, cellulose and even macro- and microalgae [5]. However, it is limited by relatively low butanol yields, the use of land-based biomass and low final butanol concentrations, resulting in high recovery costs [6]. 
An alternative production pathway is the direct conversion of $\mathrm{CO}_{2}$ into butanol within genetically engineered, autotrophic microorganisms, followed by excretion into the growth medium. This allows the recovery of butanol from the culture, whilst recycling the biomass back into the photobioreactor for further product expression and minimises the nutrient requirements for biomass growth. Autotrophic production of $n$-butanol by the cyanobacterium Synechococcus elongates 7942 was first demonstrated in 2011, after transferring a modified CoA-dependent 1-butanol production pathway into the cyanobacterium [7]. During cultivation in anoxic conditions, butanol accumulation reached up to $14.5 \mathrm{mg} \mathrm{L}^{-1}$ after seven days of culture, however the presence of oxygen (a by-product of biomass growth) was found to exert a strong inhibitory effect. Further manipulations of this strain by the same group helped to increase 1-butanol titres to $29.9 \mathrm{mg} \mathrm{L}^{-1}$ [8] and $317 \mathrm{mg} \mathrm{L}^{-1}$ [9], whilst substituting the oxygen sensitive CoA-acylating butyraldehyde dehydrogenase with an alternative, oxygen tolerant CoA-acylating aldehyde dehydrogenase. $\mathrm{N}$-butanol expression has also been demonstrated in Synechocystis sp. PCC 6803, achieving titres of up to $100 \mathrm{mg} \mathrm{L}^{-1}[10]$.

However, it was found that maximum butanol titres within the investigated host organisms are limited by significant inhibition of cell growth at butanol concentrations of $750 \mathrm{mg} \mathrm{L}^{-1}$ and above [9][11]. To address this limitation, a number of studies have been conducted to identify genes responsible for regulating butanol tolerance in Synechocystis sp. PCC 6803, to aid the development of strains with enhanced butanol tolerance [12][13]. Butanol tolerance can also be increased through long-term experimental evolution processes, as demonstrated by Wang et al. [14], who achieved a $150 \%$ increase of the butanol tolerance in Synechocystis sp. PCC 6803 (0.2 vol\% to 0.5 vol\%) after 94 passages over a 395 day period.

In all cases, it is obvious that further improvements of the butanol productivity are required, before this technology becomes commercially feasible. Particularly the high energy requirements of recovering butanol from dilute mixtures is a major concern and can easily outweigh the energy content of the final product, rendering the biofuel production process energy negative. Luyben, for example, predicted a combined heating and cooling duty of 
9.1 $\mathrm{MJ} \mathrm{kg}^{-1}$ for the recovery of butanol from a 2 mol\% mixture $\left(\sim 77.5 \mathrm{~g} \mathrm{~L}^{-1}\right)$ using a conventional distillation/decanter process, which represents a significant proportion of the butanol energy content of $36.1 \mathrm{MJ} \mathrm{kg}^{-1}$ [15]. Slightly more favourable results were obtained by Vane and Alvarez, who managed to reduce the break-even concentrations from approximately $8.5 \mathrm{~L}^{-1}$ to $5 \mathrm{~g} \mathrm{~L}^{-1}$ by implementing heat integration between the in- and outlet streams, however their model considered the heating requirements only [16].

A number of separation processes, including gas stripping, pervaporation, adsorption and liquid-liquid extraction, have been proposed as potential low-energy alternatives to distillation and were tested for the recovery of butanol from $A B E$ fermentation mixtures [17]. In-situ separation resulted in increased butanol productivity, glucose conversion and butanol concentration in broth [18]. Despite such enhancement, the system energy requirements have rarely been quantified, let alone compared against one another. Nonetheless, a good understanding of the total system energy requirements is essential to identify the best overall system configuration, and to determine the minimum butanol production targets that need to be met before autotrophic $n$-butanol production can become commercially feasible.

In the present work, the autotrophic production and recovery of biobutanol was modelled on Aspen Plus using four of the most promising butanol separation technologies: distillation, gas stripping, pervaporation and ionic liquid extraction (ILE). Each system was carefully optimised and energy integration was performed over a range of butanol concentrations (1 to $10 \mathrm{~g} \mathrm{~L}^{-1}$ ), in order to identify the best configuration and operating conditions for each separation process. This allowed the estimation of the break-even butanol concentrations at which the recovery energy equals the fuel energy content, allowing like-for-like comparison of all four separation processes and the establishing of a minimum butanol target value. Moreover, the economic potential was evaluated by determining the capital and operating costs of a pilot plant facility $\left(100 \mathrm{~kg} \mathrm{~h}^{-1}\right)$ for a $n$-butanol culture concentration of $10 \mathrm{~g} \mathrm{~L}^{-1}$. It is clear that a single study cannot cover all technology options, and the current study has been restricted to four easily implementable technologies, most relevant to the current project. Nonetheless, the current 
study provides a rigorous methodology to compare and assess different separation processes, offering a benchmark for future studies on alternative separation processes, such as adsorption.

\section{Methodology}

\subsection{Model Overview}

The autotrophic production and recovery of $n$-butanol via the four selected separation processes (distillation, gas stripping, pervaporation and ILE) was modelled in Aspen Plus V9 using the NRTL equation of state. For completeness, the algal cultivation stage was modelled using an equation-oriented model using Aspen Custom Modeller (ACM) based on published literature data, but has little impact on the downstream physical separation process. Therefore, Aspen was deemed a suitable tool to determine the energy requirements and cost estimates for the different physical separation processes. Each model consists of three stages (Figure 1): (1) a cultivation stage, containing the photobioreactor (PBR), where $\mathrm{CO}_{2}$ and water are converted into $n$-butanol, oxygen and biomass; (2) a butanol recovery stage, where butanol is removed from the culture using the selected separation technology, and (3) a polishing stage, where the recovered product is purified via phase separation and distillation to produce pure butanol. Except for minor variations to account for differences in the set-up of recycle streams and the butanol purity at the outlet of the recovery stage, all four models employ the same setup for the cultivation and polishing stages. Their main difference is therefore the choice of separation technology for the recovery of butanol from the culture and the removal of excess water to obtain a sufficiently concentrated butanol stream.

To enable like-for-like comparison of the four butanol recovery processes, the $n$-butanol production rate of each system was controlled at $1 \mathrm{~kg} \mathrm{~h}^{-1}$ by adjusting the PBR volume. The butanol concentration at the PBR outlet was set to values ranging from $1 \mathrm{~g} \mathrm{~L}^{-1}$ to $10 \mathrm{~g} \mathrm{~L}^{-1}$ by varying the dilution rate through the PBR. To account for pressure drop, all liquid and stripping 
gas recycle streams were passed through pumps or compressors to increase their pressure by 1 bar.

\subsection{Butanol production}

To model the complex growth kinetics of a butanol-producing cyanoabacteria, a custom model was developed for the PBR, based on a combined form of the Monod model, representing biomass growth, and the Logistic model, representing cyanobacteria decay (Equation 1) [19]. (The first term on the right hand side of the equation represents biomass growth, whereas the second term represents biomass decay.)

$\frac{d X}{d t}=\mu \cdot X-\mu_{d} \cdot X^{2}$

where $X$ is biomass concentration $\left(\mathrm{g} \mathrm{L}^{-1}\right), \mu$ is biomass specific growth rate $\left(\mathrm{h}^{-1}\right), X_{\max }$ is maximum biomass concentration under nutrient-sufficient conditions $\left(\mathrm{g} \mathrm{L}^{-1}\right)$, and $\mu_{d}$ is biomass specific decay rate $\left(\mathrm{L} \mathrm{g}^{-1} \mathrm{~h}^{-1}\right)$.

By assuming that both $\mathrm{CO}_{2}$ and nutrients are supplied in excess, biomass growth becomes a function of incident light and temperature only (Equation 2a). Their effects were modelled using the Aiba model (Equation 2b) and an Arrhenius type rate equation (Equation 2c), respectively, which have been previously found to be suitable models for this purpose [19].

Unlike biomass growth, biomass decay is a function of temperature only and therefore the biomass decay rate can be equated to the temperature term only:

$\mu=\mu_{m} \cdot k(I) \cdot k(T)$

$k(I)=\frac{1}{I+k_{s}+\frac{I^{2}}{k_{i}}}$

$k(T)=A_{a} \exp \left[-\frac{E_{a}}{R}\left(\frac{1}{T}-\frac{1}{T_{a}}\right)\right]$

$\mu_{d}=k_{d}(T)=A_{d} \exp \left[-\frac{E_{d}}{R}\left(\frac{1}{T}-\frac{1}{T_{d}}\right)\right]$ 
where $\mu_{m}$ is maximum biomass specific growth rate $\left(\mathrm{h}^{-1}\right), I$ is the light intensity $(\mu \mathrm{E}), k_{s}$ is the photosaturation term $(\mu \mathrm{E}), k_{i}$ is the photoinhibition term $(\mu \mathrm{E}), \mathrm{A}_{\mathrm{a}}$ and $\mathrm{A}_{d}$ are pre-exponential parameters, $E_{a}$ and $E_{d}$ are the algae activation and deactivation energies $\left(\mathrm{kJ} \mathrm{mol}^{-1}\right), T$ is the culture temperature $(K), T_{a}$ and $T_{b}$ are reference temperatures for algae growth and death, respectively, $(\mathrm{K})$, and $R$ is the gas constant $\left(8.315 \mathrm{~J} \mathrm{~mol}^{-1} \mathrm{~K}^{-1}\right)$.

To determine the parameters $k_{s}, k_{i}, A_{a}, E_{a}, A_{d}$ and $E_{d}$, the models were fitted to published growth data for the cyanobacteria Synechocysystis PCC 6803 [20], at a reference temperature of $303 \mathrm{~K}$, using a non-linear least-squares solver in Matlab (Model parameters provided in supplementary information). Substituting equations $2 a, b, c$ and $d$ into Equation 1 yields the overall differential equation describing biomass concentration (Equation 3).

$\frac{d X}{d t}=A_{a} \mu_{m} \frac{1}{I+k_{s}+\frac{I^{2}}{k_{i}}} \exp \left[-\frac{E_{a}}{R}\left(\frac{1}{T}-\frac{1}{T_{a}}\right)\right] X-A_{d} \exp \left[-\frac{E_{d}}{R}\left(\frac{1}{T}-\frac{1}{T_{d}}\right)\right] X^{2}$

In the absence of sufficient data for photoautotrophic butanol production, the ratio of butanol production to biomass growth was fixed at 0.975 . As the current model does not account for nutrient consumption (which is expected to be small for photocatalytic production), the relationship between butanol productivity and growth has a minor effect on the model results.

\subsection{Butanol recovery}

The recovery of $n$-butanol from the PBR outlet stream was modelled using the four selected separation processes. For each process, the butanol-depleted medium stream is recycled to the inlet of the PBR, whereas the butanol rich product is fed to the final polishing stage. Prior to the recovery stage, the culture is passed through a low energy filtration stage $(0.4-$ $\left.0.88 \mathrm{~kW} \mathrm{~h} \mathrm{~m}^{-3}\right)[21]$, to retain the algal cells within the PBR and prevent them from being damaged in the recovery process, with an assumed energy penalty of $0.5 \mathrm{~kW} \mathrm{~h} \mathrm{~m}^{-3}$ (inlet flow).

\subsubsection{Distillation}

Representing the most commonly used technique for the separation of alcohols, distillation was selected as the base case scenario. In this model, a single stage distillation column was 
employed to raise the butanol concentration into the immiscible phase region, allowing further purification in the polishing stage (Figure 1).

In addition to butanol and the aqueous growth medium, the recovery system inlet contains a number of dissolved reaction gases, which cannot be condensed following distillation. The distillation unit was therefore modelled using the RadFrac column option of Aspen, allowing the recovery of both gaseous and liquid streams from the condenser. To reduce the column loading, the distillation inlet is first pre-heated using $\mathrm{H}-1$, allowing the removal and recycling of non-condensable gases in flash drum V-1. The organic phase is subsequently sent to the polishing stage, whilst the aqueous phase is cooled and returned back to the PBR.

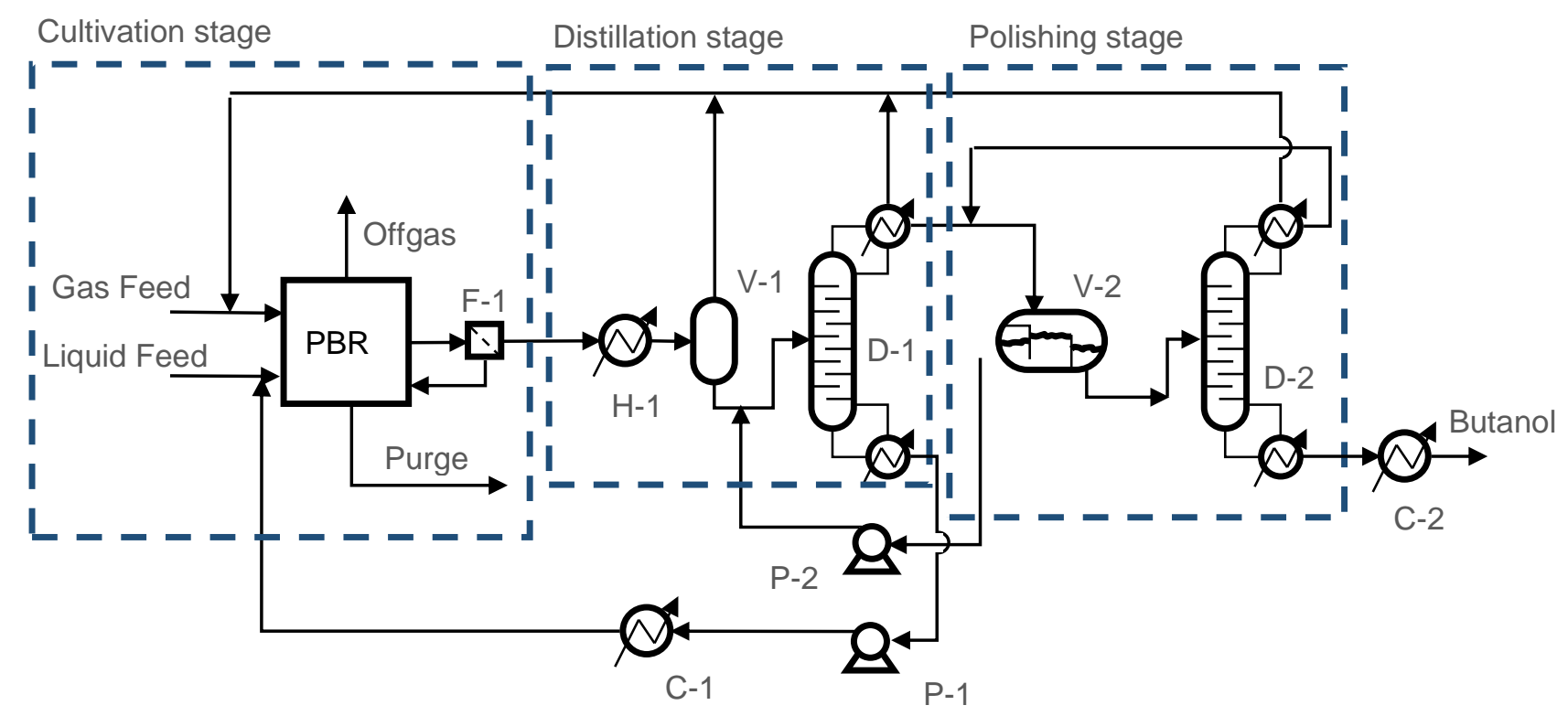

Figure 1: Schematic of system set-up for butanol recovery by distillation

\subsubsection{Gas stripping}

The gas stripping system model employs the stripping gas nitrogen to reduce the vapour pressure of $n$-butanol in the gas phase, thereby lowering the temperature required for evaporation. In order to obtain a sufficiently high butanol concentration at the polishing stage inlet, a minimum of two stripping stages are required (Figure 2). In each stage, the process stream is mixed with the stripping gas and heated to the required stripping temperature in exchangers $\mathrm{H}-1$ and $\mathrm{H}-2$. Subsequently, the combined stream is fed to a flash drum (S-1/S-2) 
to recover a butanol-rich vapour stream and allow the recycling of the butanol-depleted aqueous phase to the previous processing stage. Butanol is re-condensed in coolers C-1 and $\mathrm{C}-2$, and recovered in flash drums $\mathrm{V}-1$ and $\mathrm{V}-2$. Whilst the second-stage product is passed to the polishing stage, the stripping gas streams are recycled to the stage inlets via compressors Comp-1 and Comp-2.

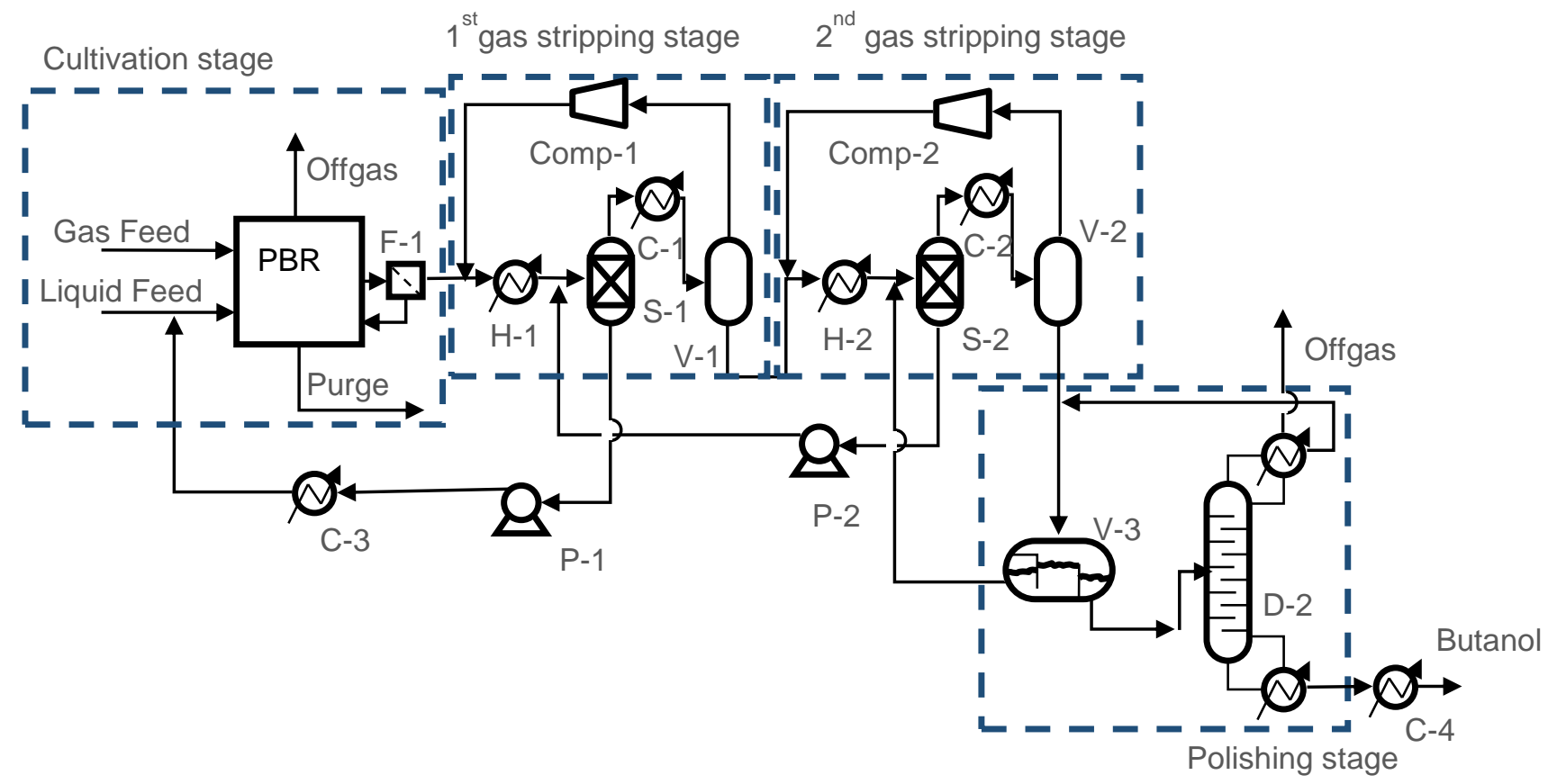

Figure 2: Schematic of system set-up for butanol recovery by gas stripping

\subsubsection{Pervaporation}

Similarly to gas stripping, the pervaporation system employs two separation stages to achieve the required butanol concentration at the polishing stage inlet (Figure 3). Preheaters $(\mathrm{H}-1$ and $\mathrm{H}-2)$ at the stage inlets raise the stream temperatures to the specified pervaporation conditions. Subsequently, the low-pressure permeate streams are passed through coolers C1 and C-2 to condense recovered butanol and water, before the non-condensables gases are pumped through compressors Comp-1 and Comp-2 to maintain the required vacuum at the pervaporator outlet. The aqueous retentate streams are recycled to the previous stage inlet via transfer pumps P-3 and P-4. 


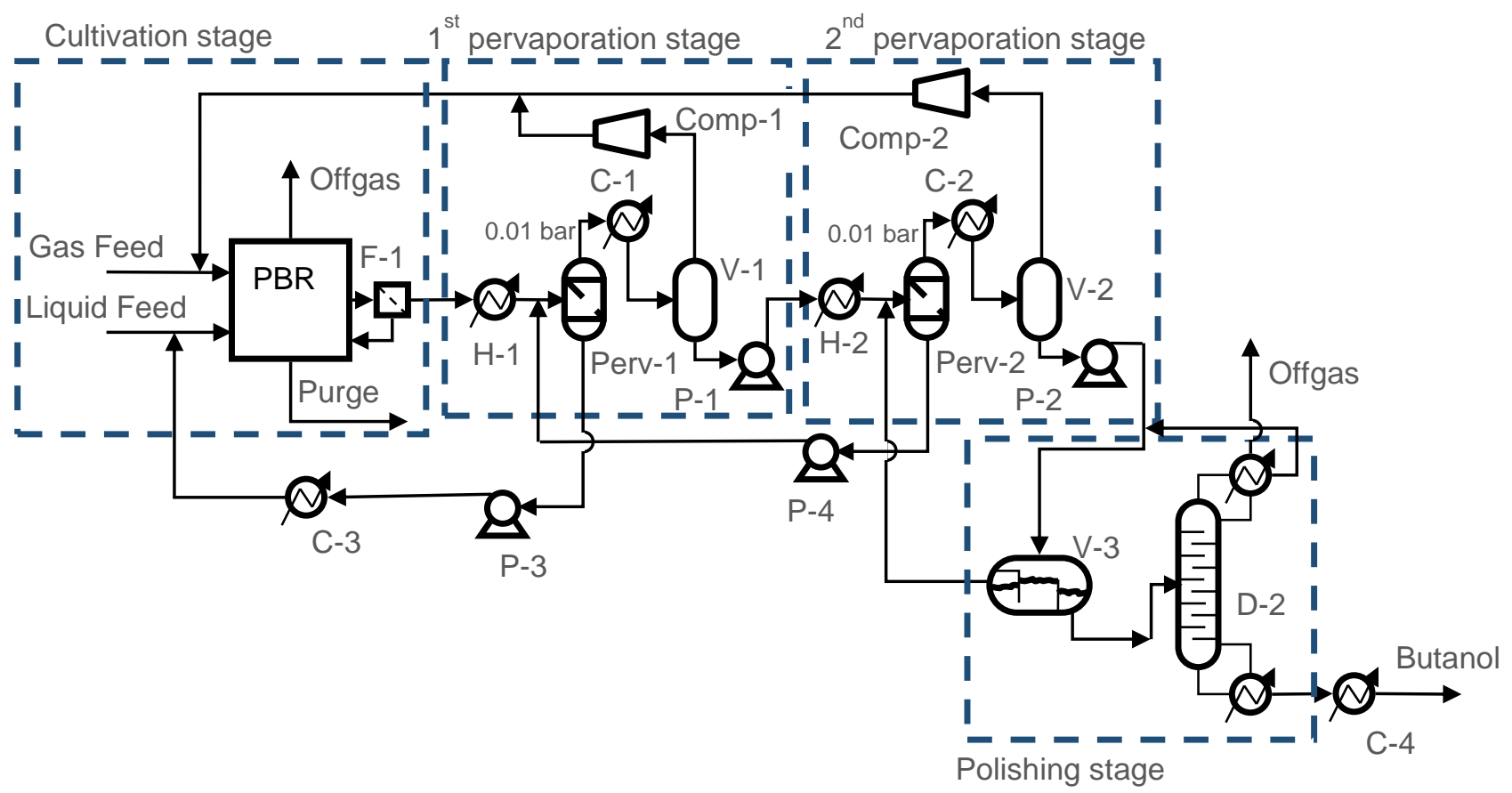

Figure 3: Schematic of system set-up for butanol recovery by pervaporation

To model the pervaporation units themselves, a custom unit operation was developed in Aspen Custom modeller, based on the following assumptions [22]:

1. Perfect mixing at either side of the membrane ensures constant compositions within the permeate and retentate streams

2. The pervaporation of vapours across the membrane represent the rate controlling step

3. The permeability of each component in the mixture is equal to that of the pure component

4. The pressure drop across the feed and permeate streams is negligible

5. Diffusion along the flowpath is negligible

Consequently, the membrane flux of each component can be described by Equation 4:

$$
J_{i}=\frac{y_{i} F_{P}}{A_{m}}=\frac{P_{i}}{\delta}\left(p_{i, f}-p_{i, p}\right)
$$

Where $\mathrm{J}_{\mathrm{i}}$ is the flux of component $i$ across the membrane, $F_{p}$ is the permeate flow, $A_{m}$ is the membrane area, $\mathrm{P}_{\mathrm{i}}$ is the membrane permeability for component $i, \delta$ is the membrane 
thickness, $\mathrm{p}_{\mathrm{i}, \mathrm{f}}$ is the partial pressure of component $i$ in the retentate, and $\mathrm{p}_{\mathrm{i}, \mathrm{p}}$ is the partial pressure of component $i$ in the permeate.

The partial pressure of each component in the retentate can be estimated from the product of its mol fraction, $x_{i}$, activity coefficient, $\gamma_{i}$, and saturation pressure, $p_{i}^{\text {sat }}$, at a given pervaporation temperature (Equation 5a), whereas the partial pressure in the permeate is the product of the permeate pressure, $p_{p}$, and its vapour mol fraction, $y_{i}$ (Equation $5 b$ ). The mol fractions of each component in the permeate, retentate and feed $\left(x_{i}\right)$ can be related using the permeate to feed flow ratio, defined as the stagecut, $\varphi$ (Equation $5 c$ ). In addition, for mass balance purposes, the individual component mass fractions in each phase must sum to unity (Equations $5 d$ and e).

$$
\begin{aligned}
& p_{i, f}=\gamma_{i} x_{i} p_{i}^{\text {sat }} \\
& p_{i, p}=p_{p} y_{i} \\
& z_{i}=(1-\varphi) x_{i}+\varphi y_{i} \\
& \sum_{i=1}^{n} x_{i}=1 \\
& \sum_{i=1}^{n} y_{i}=1
\end{aligned}
$$

After substituting equations $5 \mathrm{a}$ and $\mathrm{b}$, equation 4 can be expanded to include the permeate flow, $F_{p}$, and membrane area, $A_{m}$ (Equation 6).

$$
y_{i} F_{P}=\frac{P_{i}}{\delta}\left(\gamma_{i} x_{i} p_{i}^{s a t}-p_{p} y_{i}\right) A_{m}
$$

Permeability values for all system components were obtained from the literature for a commercial PERVAP 4060 membrane (Table 1). After specifying values for stagecut, pervaporation temperature and permeate pressure, the model is thus able to predict retentate and permeate stream compositions and the required membrane area. 


\begin{tabular}{|c|c|c|}
\hline Parameter & Value & Reference \\
\hline $\begin{array}{l}\text { Membrane } \\
\text { thickness }\end{array}$ & $6 \mu$ & [23] \\
\hline Permeabilities & $\left(\mathrm{kmol} \mathrm{m}^{-2} \mathrm{~h}^{-1} \mathrm{bar}^{-1}\right)$ & \\
\hline$P_{\text {Butanol }}$ & 2.59E-05 & $\begin{array}{c}\text { Calculated from } \\
\text { [23] }\end{array}$ \\
\hline$P_{\text {water }}$ & 4.52E-06 & $\begin{array}{c}\text { Calculated from } \\
\text { [23] }\end{array}$ \\
\hline $\mathrm{P}_{\mathrm{CO} 2}$ & $3.74 \mathrm{E}-07$ & [24] \\
\hline Poxygen & 7.47E-08 & [24] \\
\hline $\mathrm{P}_{\text {Nitrogen }}$ & 3.49E-08 & [24] \\
\hline
\end{tabular}

The pervaporator heat duty is calculated using an energy balance across the system and importing the enthalpy values for each stream. To include the pervaporator heat duties when running the Aspen energy analyser, their values were duplicated in separate heat exchangers placed on the flowsheet.

\subsubsection{Ionic liquid extraction}

The ionic liquid extraction model consists of two extraction stages, each containing 10-stage liquid-liquid extraction units (E-1 andE-2, Figure 4). Both units are operated at cultivation temperature and the ionic liquid outlet streams are subsequently heated in $\mathrm{H}-1$ and $\mathrm{H}-2$ to flash off the recovered butanol and water. The product streams are condensed in coolers C$1 \mathrm{~A}$ and $\mathrm{C}-2 \mathrm{~A}$, whereas the regenerated ionic liquid is recycled to the stage inlet, via coolers C-1B and C-2B.

The Aspen Plus database does not contain property data for ionic liquids, and consequently, these were set up manually using literature values for the binary interaction parameters for 1 - 
hexyl-3-methylimidazolium hexafluorophosphate ([hmim][PF6]) [25]. The corresponding ideal heat capacity parameters were estimated with the Aspen estimation tool using heat capacity values in the $293.15 \mathrm{~K}$ to $343.15 \mathrm{~K}$ range [26]. To reflect the negligible ionic liquid vapour pressure, the Antoine's coefficients were estimated from a nominal vapour pressure value of $1 \mathrm{~Pa}$ at $100^{\circ} \mathrm{C}$, with a molar enthalpy of vaporization of $1000 \mathrm{cal} / \mathrm{mol}$. The required input values for the critical pressure and temperature, Pitzer acentric factor (OMEGA), liquid molar volume were chosen arbitrarily, as they have no bearing on the model results.

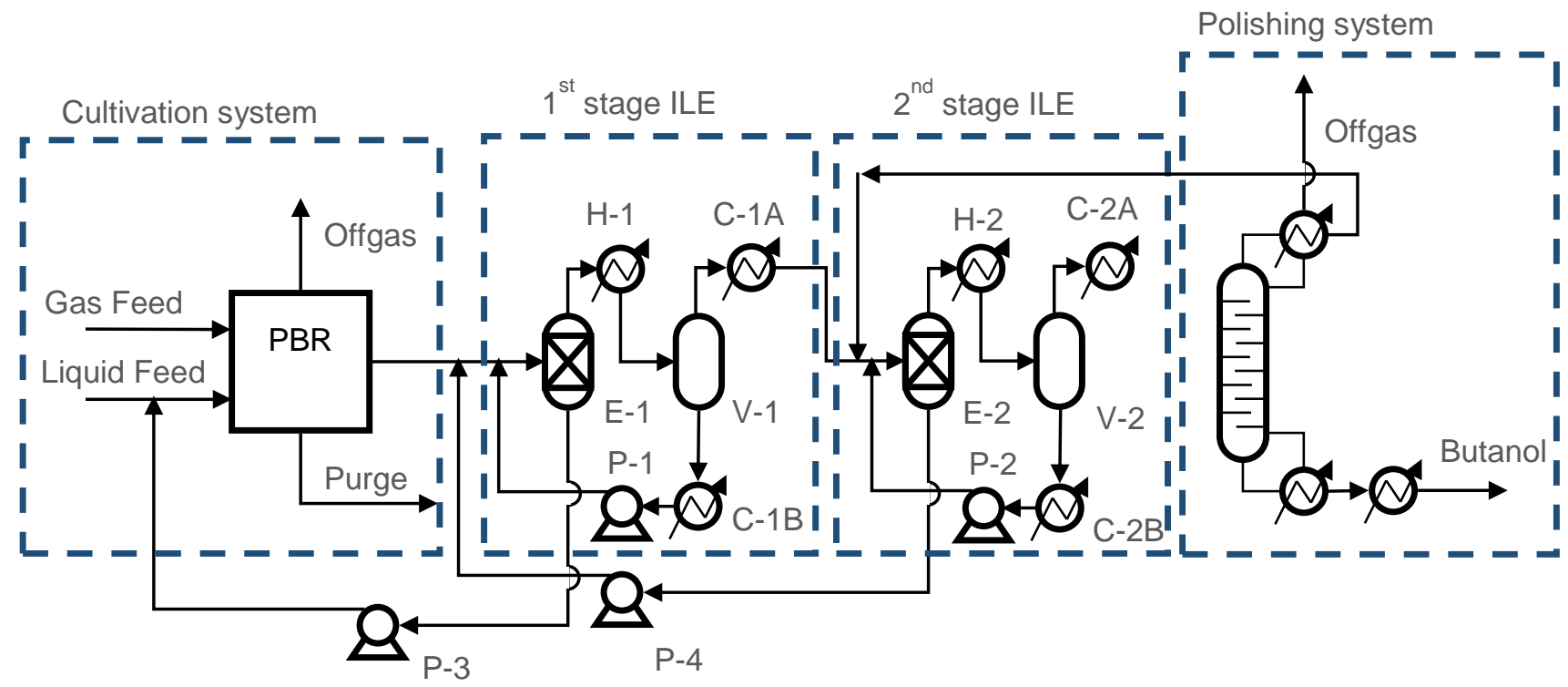

Figure 4: Schematic of system set-up for butanol recovery by ionic liquid extraction

\subsection{Polishing system}

At molar concentrations of $24.8 \%, n$-butanol forms an azeotrope with water, preventing the production of pure butanol using single-stage distillation. Similarly, none of the other three separation techniques are capable of producing pure butanol, and consequently an additional purification stage is required.

$N$-butanol and water form immiscible mixtures at butanol mol fractions ranging from 0.02 to $0.48\left(30^{\circ} \mathrm{C}\right)$, resulting in phase separation into an organic and aqueous layer. This behaviour 
can be exploited in a phase separator to raise the butanol concentration above the azeotropic value. The resulting organic phase can be subsequently distilled in a polishing column to produce pure butanol.

The phase separator was modelled with the decanter unit operation, using the UNIFAC property method and specifying water as the key $2^{\text {nd }}$ liquid phase component, and operated at $30^{\circ} \mathrm{C}$. However, this operation was not required for the ionic liquid extraction system, as the butanol concentration in the separation system outlet was sufficiently high for direct distillation. The final distillation step was modelled using a Radfrac column, containing 10 theoretical stages (feed above stage 4), a condenser temperature of $30^{\circ} \mathrm{C}$, a molar reflux ratio of 1.5 and a molar bottoms to feed ratio of 0.3 . For the IL model, to prevent the butanol concentration at the outlet of the $2^{\text {nd }} \mathrm{IL}$ stage to fall below the water/butanol azeotrope, the bottoms to feed ratio in the polishing column was reduced to 0.1 .

It should be noted that the energy requirements for the polishing column represented a very low fraction of the total system heat requirements $(\sim 1 \%)$, and consequently its operation was no further optimized to prevent associated system instabilities.

\subsection{Model optimization}

Each model was initially optimized at a butanol concentration in the PBR of $1 \mathrm{~g} \mathrm{~L}^{-1}$, in order to identify the best operating conditions for each system.

The system energy was calculated as the net sum of heating duty, $Q_{H}$, cooling duty, $Q_{C}$, and work, W, without energy integration (Equation 7).

System Energy $=\left|\sum Q_{H}\right|+\left|\sum Q_{C}\right|+\left|\sum W\right|$

The butanol recovery of each separating stage was calculated as the ratio of the butanol outlet flow, $B_{\text {out, }}$ to the total butanol inlet flow, $B_{\text {in }}$ (including recycle streams) into the separator (Equation 8). Absolute values were used to evaluate the effectiveness of individual stages 
independent of the overall system (e.g. recycles from other stages) and thereby enable easier comparison with alternative system configurations.

Recovery $=\frac{B_{\text {out }}}{B_{\text {in }}}$

The butanol selectivity was calculated as the ratio of the butanol recovery to the recovery of all other products (Equation 9).

Selectivity $=\left(\frac{B_{\text {out }}}{B_{\text {in }}}\right) \times\left(\frac{F_{\text {in }}-B_{\text {in }}}{F_{\text {out }}-B_{\text {out }}}\right)$

Where $F_{\text {in }}$ and $F_{\text {out }}$ are the total inlet and outlet flows, respectively.

After determining the optimal separation parameters, yielding the lowest total system energy consumption, the energy requirements were integrated using the Aspen Energy Analysis tool and re-optimised if necessary. Subsequently, the separation systems were optimized at butanol concentrations of up to $10 \mathrm{~g} \mathrm{~L}^{-1}$, to determine the corresponding system energy requirements. As the butanol concentration generally had a relatively small impact on the optimal operating parameters, the results and discussion section only includes data for the lowest butanol concentrations of $1 \mathrm{~g} \mathrm{~L}^{-1}$. Optimized values for higher butanol concentrations are discussed in Appendix A.

\subsection{Capital and operating cost estimation}

The total capital and operating costs for each separating system (excluding the PBR) were estimated using the Aspen Process Economic Analyzer at a PBR butanol concentration of $10 \mathrm{~g} \mathrm{~L}^{-1}$ Capital costs for the pervaporation units were based on the costs of the pervaporation membrane, which was quoted at $\$ 1350 \mathrm{~m}^{-2}$ (Interstate Speciality Products). The costs for the ionic liquid extraction units were calculated from an assumed ionic liquid cost of $\$ 100 \mathrm{~L}^{-1}$.

\section{Results and discussion}

This section contains a detailed presentation and discussion of the modelling results of the PBR (3.1) and the four different separation systems (3.2 - 3.5). Readers interested in the comparison of the 
overall energy requirements and cost estimates for the different separation technologies are referred to Sections 3.6 and 3.7.

\subsection{PBR model}

The dynamic growth model for the PBR was based on experimental data for the cyanobacterium Synechocysystis PCC 6803 [20], which is one of the strains applied to excreted butanol production. The effect of cultivation temperature and light intensity on biomass growth was well represented by the selected Aiba and Arrhenius type equations, allowing optimization of the operating conditions, with respect to the net biomass growth rate (Figure 5). The growth profile shows a typical relationship with respect of temperature, initially increasing as the cultivation temperature is raised from $14^{\circ} \mathrm{C}$ to $34^{\circ} \mathrm{C}$, followed by a rapid drop as the temperature is increased further and the decay term of the growth equation (second term of Equation 3) takes over.

The optimal region for light intensity is much broader, ranging from around 300 to $800 \mu \mathrm{mol}$ (photon) $\mathrm{m}^{-2} \mathrm{~s}^{-1}$. However, it is obvious that the light usage efficiency drops with increasing light intensity, as the overall growth rate remains constant. Therefore the PBR should be operated close to $34^{\circ} \mathrm{C}$ and at light intensities around $200 \mu \mathrm{mol}$ (photon) $\mathrm{m}^{-2} \mathrm{~s}^{-1}$, near the lower end of the maximum region.In reality, as local light intensities within the PBR are strongly dependent on the reactor type, configuration and operation, they may need to be optimised on a case-by-case basis $[27,28]$.

As the development of butanol excreting microorganisms is still in its infancy, no reliable data exists to allow accurate modelling of the relationship between biomass growth and butanol productivity. Consequently, the butanol to biomass production ratio was arbitrarily set to 0.975 , which at typical biomass concentrations corresponds to butanol titres of approximately $1 \mathrm{~g} \mathrm{~L}$ ${ }^{1}$. Based on similar works with other product excreting strains, it is expected that the optimal conditions for butanol formation are significantly different to those for biomass growth [29][30], and consequently the model needs to be adjusted to include separate growth and butanol production terms once sufficient data is available. Whilst this will have an important impact on 
the sizing and operation (nutrient requirement, production of waste biomass) of the PBR, the impact on the downstream physical separation process is minor. (The current study is predominantly focused on the energies of separation, using absolute concentrations of butanol irrespective of biomass concentrations)

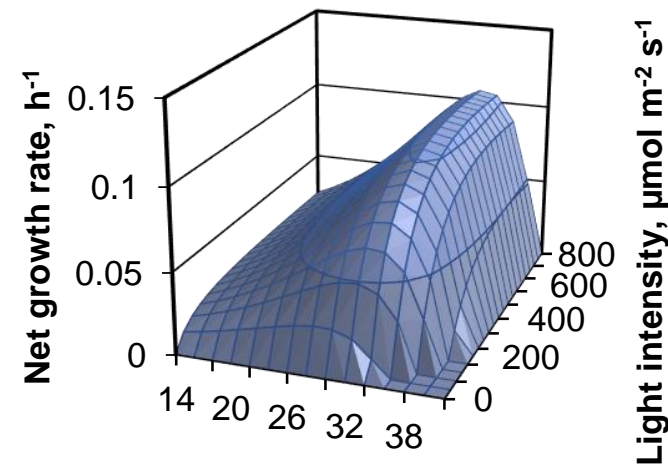

Temperature, ${ }^{\circ} \mathrm{C}$

Figure 5: Effect of cultivation conditions on growth of Synechocystis PCC 6803

\subsection{Distillation}

The distillation model employs a single distillation column to raise the butanol concentration at the phase separator inlet into the immiscible phase region. To optimize the system, a sensitivity analysis was run on the two operating specification of the distillation column, the molar reflux ratio (MRR) and the distillate to feed mass ratio (DFMR), to evaluate their impact on the cumulative system energy requirements (Figure 6a).

The results show a broad optimum region around a minimum energy value of $192.3 \mathrm{~kW}$ at a MRR of 1.0 and a DFMR of 0.0065 . Raising the MRRs and DFMRs causes only a gradual increase in energy requirements, whereas low reflux ratios and low DFMRs result in sharp increases in the system energy and the model becomes unstable. Similarly, the energy requirements start to increase at high MRRs and DFMRs.

These trends can be explained as a function of the selectivity (Figure 6b) and recovery of butanol from the distillation column (Figure 6c). Increasing the DFMR results in a significant reduction in the column selectivity, as increasing amounts of water are carried over into the 
distillate. This increases the recycle flow from the decanter to the distillation column, increasing the distillation column duty and work associated with pumping. However, as the decanter recycle flow is two to three orders of magnitudes smaller than the distillation inlet flow from the PBR. the overall impact on the system energy requirements is relatively small.

At low DFMRs, the butanol concentration in the distillate approaches the limiting azeotropic value, causing the recovery of butanol to drop off. This causes the butanol concentrations at the PBR inlet to increase, reducing the uptake capacity of the growth medium and resulting in an increase in the system flowrate from $1134 \mathrm{~kg} \mathrm{~h}^{-1}$ at a DFMR of 0.007 , to $1834 \mathrm{~kg} \mathrm{~h}^{-1}$ at a ratio of 0.004 . As the system energy requirements are predominantly associated with the heating and cooling of the distillation inlet and recycle streams, and the column duty itself, any increase in the PBR flowrate has a big negative impact on the total energy requirements of the system. This can be partially mitigated by increasing the MRR, increasing the efficiency of the butanol-water separation and therefore the butanol selectivity. Consequently, at high reflux ratios, the optimum DFMR is reduced, resulting in the interdependence observed during the energy analysis.

Further sensitivity analyses were conducted on the column inlet temperature, the number of theoretical stages and the feed location (supplementary information), indicating an optimal value of nine theoretical stages (close to the specified value of 10). As the feed was subcooled, its location had a marginal impact on the system energy requirements and was therefore kept at 5. Increasing the column feed temperature from $30^{\circ} \mathrm{C}$ to $60^{\circ} \mathrm{C}$ had no noticeable impact, whereas further temperatures increases caused the system energy requirements to increase. This finding can be explained by the partial vaporisation of butanol within the flush drum upstream of the distillation columns at temperatures above $60^{\circ} \mathrm{C}$, causing it to be recycled back to the PBR and reducing the system efficiency. 


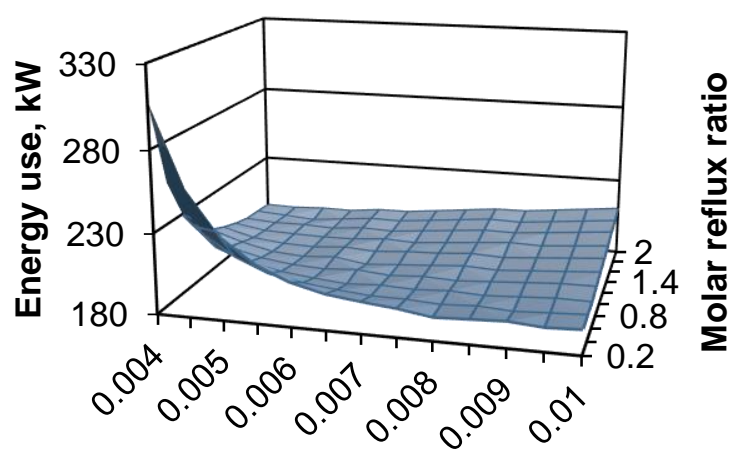

(a)

\section{Distillate to feed mass ratio}

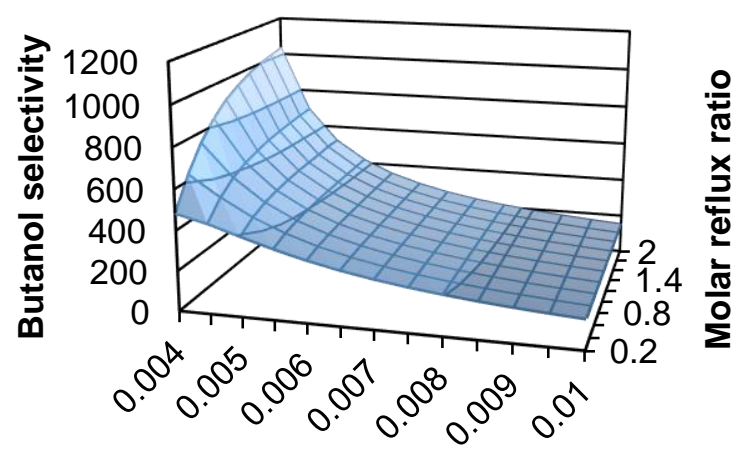

(b)

\section{Distillate to feed mass ratio}

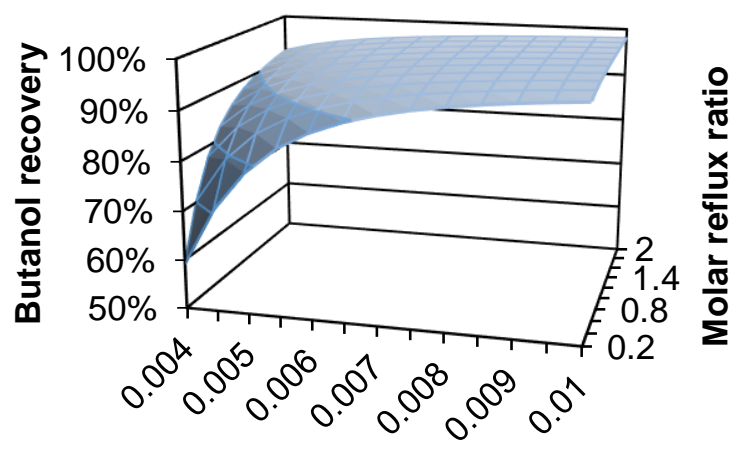

(c)

\section{Distillate to feed mass ratio}

Figure 6: Optimisation results for distillation model. Effect of operating specifications of distillation column on (a) total system energy requirements, (b) butanol selectivity, (c) butanol recovery in distillate.

The above energy optimisation was based on the cumulative system energy requirements, without any heat integration. At the optimised conditions (DFMR: 0.0065; MRR: 1.0; number 
of theoretical stages: 10 ; Feed temperature: $60^{\circ} \mathrm{C}$ ) the total system energy reached $192.7 \mathrm{~kW}$, which is predominantly associated with the heating $(96.5 \mathrm{~kW})$ and cooling $(96.2 \mathrm{~kW})$ duties, whereas the work duty associated with the filtration and pumping of the recycle streams was small $(0.63 \mathrm{~kW})$.

\begin{tabular}{|c|c|c|c|c|c|c|c|}
\hline \multirow{2}{*}{ Distillation inlet } & \multicolumn{3}{|c|}{ Before energy integration } & \multicolumn{3}{c|}{ After energy integration } \\
\cline { 2 - 8 } temperature, ${ }^{\circ} \mathrm{C}$ & $\begin{array}{c}\text { Heat } \\
\text { duty, } \\
\mathrm{kW}\end{array}$ & $\begin{array}{c}\text { Cooling } \\
\text { Duty, } \mathrm{kW}\end{array}$ & $\begin{array}{c}\text { Total, } \\
\mathrm{kW}\end{array}$ & $\begin{array}{r}\text { Heat } \\
\mathrm{duty} \\
\mathrm{kW}\end{array}$ & $\begin{array}{c}\text { Cooling } \\
\text { Duty, } \mathrm{kW}\end{array}$ & $\begin{array}{c}\text { Total, } \\
\mathrm{kW}\end{array}$ & $\begin{array}{c}\text { Energy } \\
\text { savings }\end{array}$ \\
\hline 30 & 94.3 & 94.0 & 188.9 & 94.3 & 94.0 & 188.3 & 0 \\
\hline 60 & 96.5 & 96.2 & 192.7 & 59.2 & 58.9 & 118.0 & 38.7 \\
\hline 70 & 100.8 & 100.4 & 201.2 & 48.6 & 48.2 & 96.8 & 51.9 \\
\hline 80 & 120.3 & 120.3 & 240.6 & 41.4 & 41.5 & 82.8 & 65.6 \\
\hline 90 & 223.01 & 219.3 & 442.2 & 49.4 & 45.6 & 95.1 & 78.5 \\
\hline 95 & 498.3 & 473.2 & 971.5 & 122.3 & 97.4 & 219.7 & 77.4 \\
\hline
\end{tabular}

Table 2: Effect of distillation column inlet temperature on heating and cooling duty of distillation $\underline{\text { system before and after energy integration }}$

By applying heat integration between the heating and cooling streams, the total system energy requirements can be reduced substantially (

Table 2). At $60^{\circ} \mathrm{C}$, the system duty is reduced from $192.7 \mathrm{~kW}$ to $118.0 \mathrm{~kW}$, representing a $38.7 \%$ saving. All of these savings are associated with the column preheater and the column bottoms recycle cooler, as it is not possible to integrate the energy from the reboiler and condenser for the two distillation columns. Consequently, decreasing the column inlet temperature from $60^{\circ} \mathrm{C}$ to $30^{\circ} \mathrm{C}$ eliminates the potential for heat integration, increasing the system energy requirements to $188.3 \mathrm{~kW}$. In contrast, increasing the column inlet temperature to $70{ }^{\circ} \mathrm{C}$ and $80^{\circ} \mathrm{C}$ reduces the integrated heat duty to $96.8 \mathrm{~kW}$ and $82.8 \mathrm{~kW}$, respectively, 
even though the total system energy increases to $201.2 \mathrm{~kW}$ and $240.6 \mathrm{~kW}$. At even higher inlet temperatures of $90^{\circ} \mathrm{C}$, the heat integration savings no longer compensate for the reduction in system efficiency, causing the integrated system duty to increase.

\subsection{Gas stripping}

The most important operating parameters for gas stripping are the stripping temperature and stripping gas flow rates, relative to the process flow rates. Initially, the impact of the $1^{\text {st }}$ and $2^{\text {nd }}$ stage stripping gas to flow ratios (SGFR) was determined at a constant stripping temperature of $80^{\circ} \mathrm{C}$ (Figure 7a). This revealed a clear optimum region at $1^{\text {st }}$ stage SGFRs between 0.10 and 0.12 and $2^{\text {nd }}$ stage ratios of 0.3 . The higher value for the optimum $2^{\text {nd }}$ stage ratio can be attributed to the reduced overall second stage inlet flow, whilst the amount of butanol to be recovered remains approximately equal. As the overall energy requirements appeared more sensitive to changes in the $1^{\text {st }}$ stage ratio than the $2^{\text {nd }}$ stage ratio, the analysis was repeated with a fixed $2^{\text {nd }}$ stage SGFR of 0.3 , whilst optimizing the first stage ratio and stripping temperature (Figure 7b). The results show that an increase in stripping temperature reduces the optimal SGFR leading to a minimum system energy requirement of $564.6 \mathrm{~kW}$ at a SGFR of 0.05 and a stripping temperature of $86^{\circ} \mathrm{C}$. This can be attributed to the increase in butanol vapour pressure as the stripping temperature is increased and consequently less dilution with stripping gas is required to achieve the same degree of butanol recovery (Supplementary information). Improved butanol recovery reduces the butanol recycling to the PBR and therefore results in lower system flowrates and upstream energy requirements. At the same time, increasing the stripping ratio and temperature also results in a steady decline in butanol selectivity from 18.6 to 7.5 as the amount of water carried over is increased 


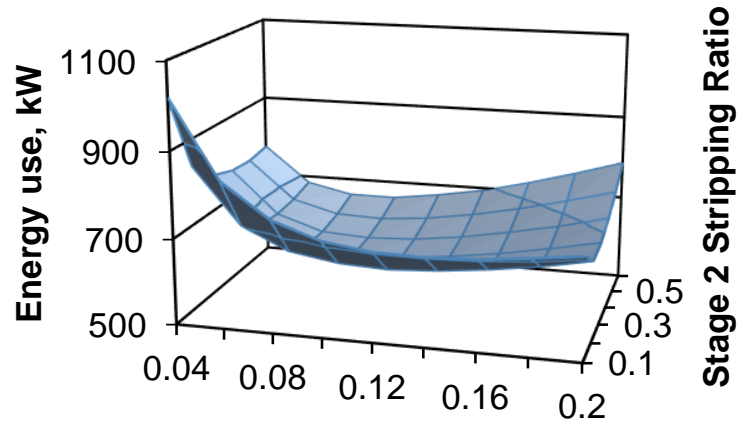

Stage 1 Stripping ratio

(a)

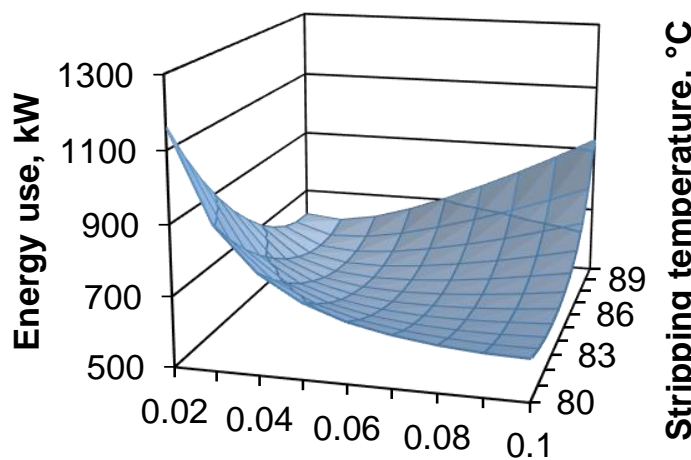

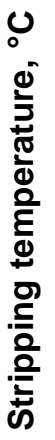

(b)

Stage 1 Stripping ratio

Figure 7: Optimisation results for gas stripping model. (a) Effect of 1st and 2nd stage stripping gas to process flow ratios, (b) Effect of 1 st stage stripping gas to process flow ratio and stripping temperature.

The temperatures of the stripping gas condensers were found to have a relatively minor effect on the system performance, provided they were sufficiently low to condense out the majority of butanol (results not shown). Therefore, the condenser temperature was kept at its optimal temperature of $20^{\circ} \mathrm{C}$ for all subsequent modelling to evaluate the heat integration potential of the gas stripping system.

\subsection{Pervaporation}

Initially, the pervaporation system was modelled with constant pervaporation temperatures of $60{ }^{\circ} \mathrm{C}$, to investigate the effect of varying the $1^{\text {st }}$ and $2^{\text {nd }}$ stage stagecuts (Figure $8 \mathrm{a}$ ). The results show a clear optimum value for the $1^{\text {st }}$ pervaporation stage stagecut of 0.03 , whereas 
the impact of the second stage ratio on the overall system energy requirements is much lower. This is unsurprising, as the heat duty of the $1^{\text {st }}$ stage is an order of magnitude higher than for the second stage, where only a fraction of the $1^{\text {st }}$ stage flow is processed.Consequently, the effect of varying the pervaporation temperature at different $1^{\text {st }}$ stage pervaporation stagecuts was investigated (Figure 8b). This revealed an optimum region at stagecuts between 0.02 and 0.04 and pervaporation temperatures between $60^{\circ} \mathrm{C}$ and $70{ }^{\circ} \mathrm{C}$ and unlike the distillation and gas stripping system, the two optima appear to be independent of each other.

The trends for butanol selectivities (Figure 8c) and recoveries (Figure 8d) show opposite effects with regards to stagecut values. Increasing the stagecut increases butanol recovery, but reduces selectivity, and consequently a compromise must be found between the upstream (excessive butanol recycling) and downstream (excessive water carry-over) energy requirements. In contrast, both selectivity and recovery are increased at higher pervaporation temperatures. Nonetheless, the increase in the pervaporation efficiency must be balanced against the increase in the associated heating and cooling requirements. An interesting observation are the low butanol selectivities at low pervaporator temperatures. These can be attributed to the low butanol vapour pressures at these temperatures, increasing the relative fraction of the gaseous components (oxygen, nitrogen and carbon dioxide) that are transferred across the membrane. Due to the low permeate stream pressure $(0.01 \mathrm{bar})$, the condenser temperatures must be kept at a value of $5^{\circ} \mathrm{C}$ or lower, to ensure the condensation of butanol in the knock-out pots. Meanwhile, increasing the pervaporation outlet pressure from 0.01 to 0.1 bar results in a steady increase in system energy requirements, as the butanol flux across the membrane is reduced, whilst the membrane area also increases by an order of magnitude from $24.8 \mathrm{~m}^{2}$ to $113.0 \mathrm{~m}^{2}$.

Similar to the distillation option, considering energy integration increasing the optimum pervaporation temperature to a value between $80^{\circ} \mathrm{C}$ and $90^{\circ} \mathrm{C}($ 


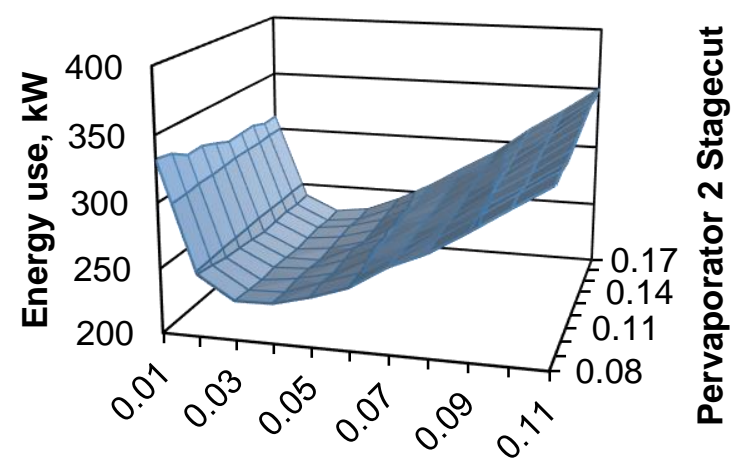

Table 3). (a)

Pervaporator 1 Stagecut 

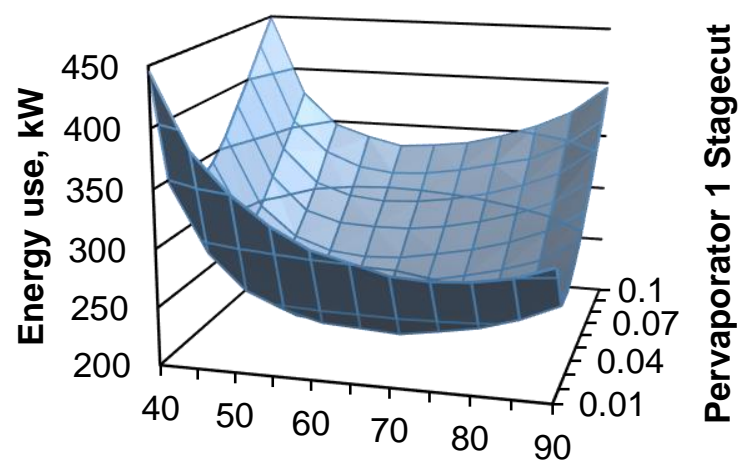

(b)
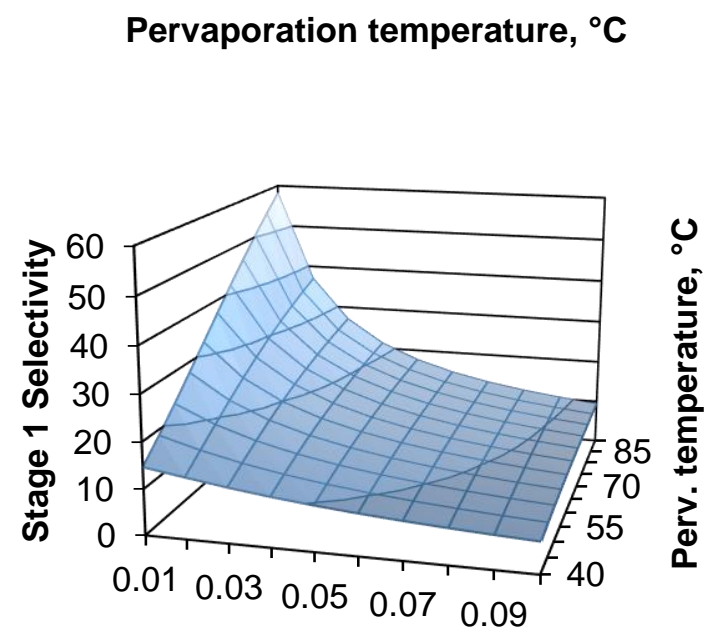

(c)

Pervaporator 1 Stagecut

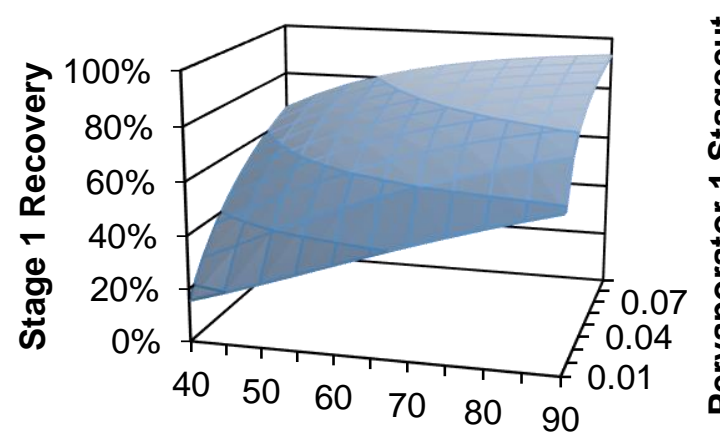

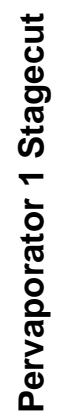

Pervaporation temperature, ${ }^{\circ} \mathrm{C}$

(d)

Figure 8: Optimisation results for pervaporation model. (a) Effect of 1st and 2nd stage stagecut ratios, (b - d) Effect of 1st stage stagecut ratio and pervaporation temperature on (b) system energy requirements, (c) butanol selectivity, (d) butanol recovery. 


\begin{tabular}{|c|c|c|c|c|c|c|c|}
\hline $\begin{array}{c}\text { Pervaporation } \\
\text { temperature, } \\
{ }^{\circ} \mathrm{C}\end{array}$ & Heat & Cooling & Total, & Heat & Cooling \\
$\mathrm{kW}$ & Duty, $\mathrm{kW}$ & $\mathrm{kuty}, \mathrm{kW}$ & Dotal, & Energy \\
$\mathrm{kW}$ & savings, \\
\hline 60 & 112.3 & 111.1 & 223.4 & 63.8 & 62.6 & 126.5 & $42.9 \%$ \\
\hline 70 & 113.4 & 112.5 & 225.9 & 53.9 & 53.0 & 106.9 & $52.6 \%$ \\
\hline 80 & 119.0 & 117.9 & 236.9 & 48.9 & 47.9 & 96.7 & $59.2 \%$ \\
\hline 90 & 133.5 & 131.0 & 264.5 & 49.2 & 46.7 & 95.9 & $63.5 \%$ \\
\hline 95 & 159.2 & 152.1 & 311.4 & 58.3 & 51.3 & 109.6 & $64.6 \%$ \\
\hline
\end{tabular}

Table 3: Effect of pervaporation temperature on energy requirements of pervaporation system $\underline{\text { before and after energy integration }}$

\subsection{Ionic liquid extraction}

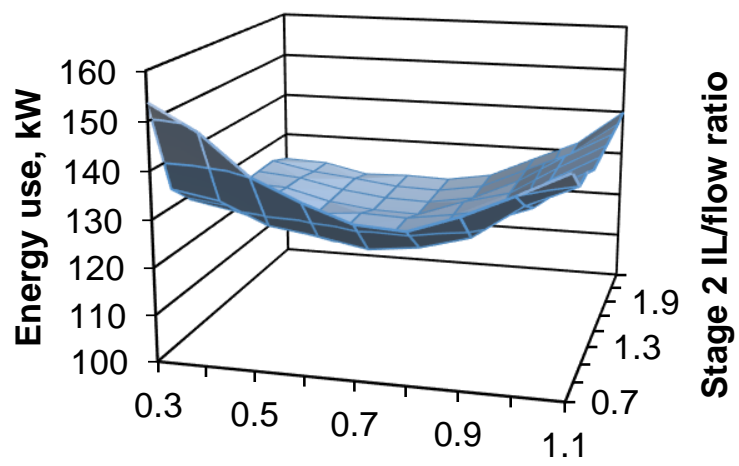

(a)

$$
\text { Stage } 1 \text { IL/flow ratio }
$$

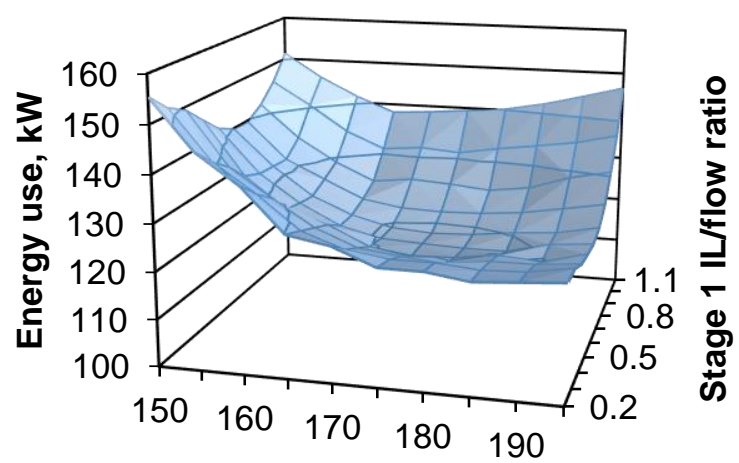

(b)

Flash Temperature, ${ }^{\circ} \mathrm{C}$ 


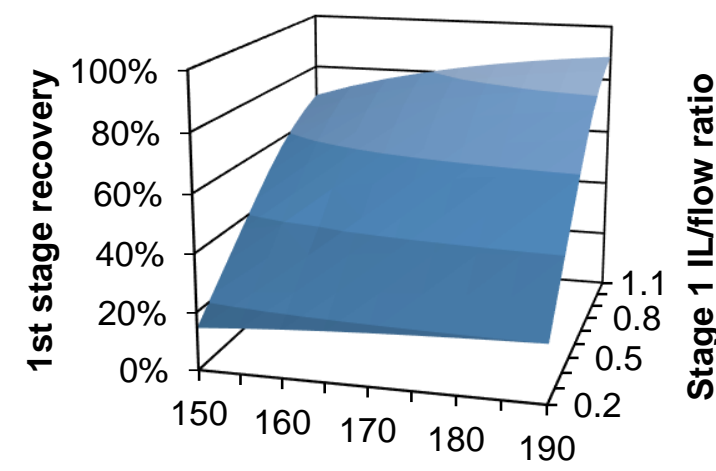

(c)

Flash Temperature, ${ }^{\circ} \mathrm{C}$

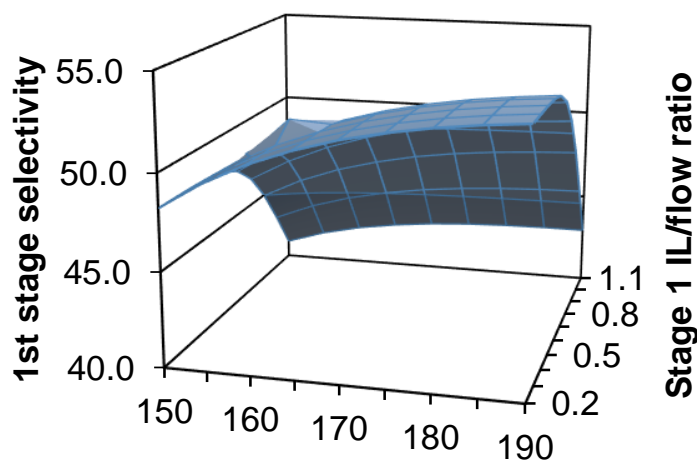

(d)

Flash Temperature, ${ }^{\circ} \mathrm{C}$

Figure 9: Optimisation results for IL extraction model. (a) Effect of 1 st and 2 nd stage IL to flow ratios, (b - d) Effect of 1 st stage IL to flow ratio and flash temperature on (b) system energy requirements, (c) butanol recovery, (d) butanol selectivity.

The ionic liquid extraction model was first run at a constant flash temperature of $170{ }^{\circ} \mathrm{C}$, whilst varying the $1^{\text {st }}$ and $2^{\text {nd }}$ stage ionic liquid to feed ratios (ILFR, Figure 9a). To prevent the butanol concentration at the outlet of the $2^{\text {nd }} \mathrm{IL}$ stage to fall below the water/butanol azeotrope, the bottoms to feed ratio in the polishing column was reduced to 0.1 . The lowest system energy was obtained at $1^{\text {st }}$ stage ILFRs between 0.6 and 0.7 , whereas at values above around 1.5, the $2^{\text {nd }}$ stage ratio had little impact on the energy requirements.

Consequently, the model was rerun with a fixed $2^{\text {nd }}$ stage ILFR of 1.5 , whilst varying the $1^{\text {st }}$ stage ratio and flash temperature (Figure 9b). In this case, an optimal region is observed at temperatures ranging from $170{ }^{\circ} \mathrm{C}$ to $180^{\circ} \mathrm{C}$ and ILFRs of 0.5 to 0.7 . 
Increasing the $1^{\text {st }}$ stage ILFR from 0.2 to 1.1 results in a 4 - to 5 -fold increase in butanol recovery (Figure 9c). As a result, the system flowrate through the PBR can be substantially reduced from $1295 \mathrm{~kg} \mathrm{~h}^{-1}$ to $5958 \mathrm{~kg} \mathrm{~h}^{-1}\left(175^{\circ} \mathrm{C}\right)$. Whilst this has a relatively minor effect on the system energy requirements, as the process flow is processed at the cultivation temperature, and therefore requires no heating or cooling, the increase in flowrate would result in a significant increase in the upstream capital costs, as well as having potentially adverse effects on the algae culture itself. Decreasing the ILFR from 1.1 to 0.6 results in a small reduction in the total IL flow from $1417 \mathrm{~kg} \mathrm{~h}^{-1}$ to $1187 \mathrm{~kg} \mathrm{~h}^{-1}$, but further reductions cause the IL flow to increase, as the IL reaches its butanol saturation limit.

Increasing the IL flash temperature from $150^{\circ} \mathrm{C}$ to $195^{\circ} \mathrm{C}$ increases the butanol recovery by up to $50 \%$, as the uptake capacity of the regenerated IL is increased (less residual butanol). However, as the temperature increases above $185^{\circ} \mathrm{C}$, the incremental increase in IL capacity is outweighed by the additional heating and cooling requirements, resulting in the system energy to increase. These results are also demonstrated by the trends in the $1^{\text {st }}$ stage butanol selectivity, which increase with reducing ILFR and increasing flash temperatures (Figure 9d). However, at IL/flow ratios below 0.6 and temperatures above $175^{\circ} \mathrm{C}$ the incremental increase in butanol selectivity is negligible, and therefore the system should not be operated beyond these values.

\subsection{Comparison of separation technologies}

\subsubsection{Energy requirements}

Using the modelling results for the individual separation processes, it is possible to extrapolate the data to predict the break-even butanol concentrations at which the separation energy drops below the energy content of the fuel (Figure 10). This reveals significant differences in the energy requirements of the different separation technologies. 


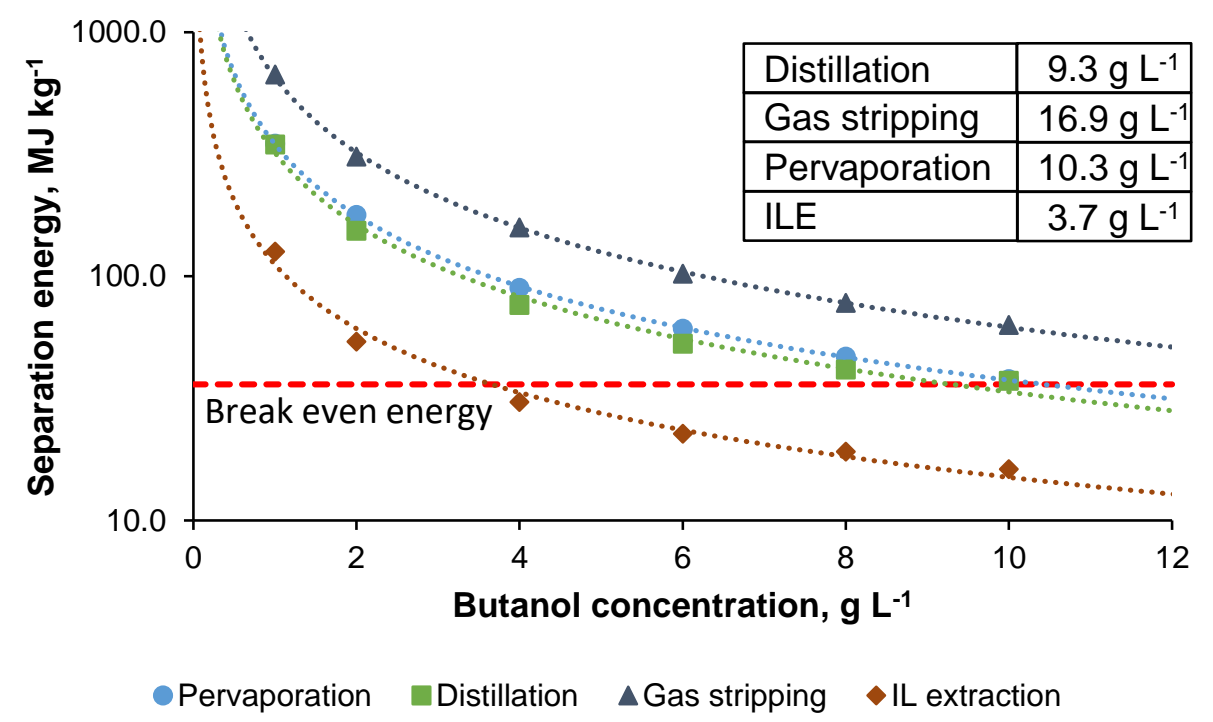

Figure 10: Comparison of butanol break-even concentrations for different separation $\underline{\text { technologies }}$

For the baseline scenario (distillation), the model predicts a break-even butanol concentration of $9.3 \mathrm{~g} \mathrm{~L}^{-1}$. Whilst this is higher than the value obtained by Vane and Alvarez $\left(\sim 5 \mathrm{~g} \mathrm{~L}^{-1}\right)[16]$, their work did not include the cooling duties, which account for almost $50 \%$ of our energy value. These results also compare favourably to those by Luyben, who estimated an energy penalty of $9.1 \mathrm{MJ} \mathrm{kg}^{-1}$ at a butanol concentration of $77.5 \mathrm{~g} \mathrm{~L}^{-1}$ only for the operation of the distillation column [15], compared to $9.4 \mathrm{MJ} \mathrm{kg}^{-1}$ from our model for the whole separation system.

The results for the gas stripping model, with a break-even concentration of $16.9 \mathrm{~g} \mathrm{~L}^{-1}$, suggest that this technology is significantly less efficient than the baseline distillation scenario and therefore appears unsuitable for the recovery of butanol from dilute mixtures. This can be attributed to the high energy requirements of heating and cooling of the stripping gas, and increased latent heat losses as a result of the low separation selectivity, which exceed the energy savings associated with reducing the evaporation temperature from $99^{\circ} \mathrm{C}$ at the distillation bottom to $83^{\circ} \mathrm{C}$ in the stripping column $\left(10 \mathrm{~g} \mathrm{~L}^{-1}\right)$. However, as the stripping temperature reduces with increasing butanol concentrations, it is possible that gas stripping 
becomes more suitable for the recovery of butanol from more concentrated fermentation cultures, which are closer to the immiscible phase region.

At low butanol concentrations, the energy requirements for pervaporation are very similar to those for the base case scenario, but are slightly increased at higher concentrations, resulting in a higher break-even concentration of $10.3 \mathrm{~g} \mathrm{~L}^{-1}$, compared to $9.3 \mathrm{~g} \mathrm{~L}^{-1}$ for distillation. These results can be predominantly attributed to the low condenser temperatures $\left(<5^{\circ} \mathrm{C}\right)$ required for the pervaporator outlet streams, reducing the potential for heat integration from $78.5 \%$ for distillation, to $63.5 \%$ for pervaporation. Consequently, the energy use after heat integration exceeds that of distillation, despite a much lower total energy use of $264.5 \mathrm{~kW}$ (compared to $442.2 \mathrm{~kW}$ for distillation). A potential solution could be the compression of the permeate stream prior to condensation, however the compression of the non-ideal fluids (water and butanol) results in temperatures of several hundreds of degrees, requiring a number of intercooling stages.

Finally, the energy requirements for IL extraction are much lower than for distillation, with a break-even concentration of only $3.7 \mathrm{~g} \mathrm{~L}^{-1}$. This can be mostly attributed to the elimination of the heating and cooling of the main PBR process stream, as the liquid extraction can be conducted at cultivation temperature. In addition, the subsequent recovery of butanol from the ionic liquid is very efficient, due to the negligible vapour pressure of the solvent.

\subsection{Economic considerations}

To evaluate the capital and operating costs associated with the recovery of butanol via the different technologies, the models were analysed using the Aspen Process Economic Analyzer, for a pilot scale facility producing $100 \mathrm{~kg}$ of butanol per hour at a concentration of $10 \mathrm{~g} \mathrm{~L}^{-1}$ (Error! Reference source not found.).

\begin{tabular}{|l|l|l|l|l|}
\hline Technology & Equipment cost & Capital cost & Utilities cost & Operating costs \\
\hline Distillation & $\$ 1,445 \mathrm{k}$ & $\$ 5,827 \mathrm{k}$ & $\$ 503.6 \mathrm{k}$ & $\$ 1,810 \mathrm{k}$ \\
\hline Pervaporation & $\$ 3,158 \mathrm{k}$ & $\$ 9,161 \mathrm{k}$ & $\$ 478.1 \mathrm{k}$ & $\$ 2,178 \mathrm{k}$ \\
\hline
\end{tabular}




\begin{tabular}{|l|l|l|l|l|}
\hline Gas stripping & $\$ 2,902 \mathrm{k}$ & $\$ 8,522 \mathrm{k}$ & $\$ 856.4 \mathrm{k}$ & $\$ 2,578 \mathrm{k}$ \\
\hline IL extraction & $\$ 2,655 \mathrm{k}$ & $\$ 6,895 \mathrm{k}$ & $\$ 542.0 \mathrm{k}$ & $\$ 1,520 \mathrm{k}$ \\
\hline
\end{tabular}

Table 4: Cost estimations for the four separation technologies at a butanol concentration of $10 \mathrm{~g} \mathrm{~L}^{-1}$ and production rate of $100 \mathrm{~kg} \mathrm{~h}^{-1}$

Unlike the energy requirements, the total installed cost for the distillation baseline scenario is significantly lower than for the other three systems. In the case of IL extraction, the recovery cost is significantly increased due to the cost of the ionic liquid solvent itself $(\$ 1,272 \mathrm{k})$, whereas the high costs of the pervaporation and gas stripping system can be mostly attributed to the costs of the gas compressors. In contrast, the pervaporation membranes contribute a relatively minor fraction to the total installed costs $(\$ 62,838)$. From these results, it would be desirable to find a cheaper recovery solvent, but unfortunately it is very difficult to find solvents that are both hydrophobic and have a sufficiently high interaction with butanol. Nonetheless, it is likely that as ILs become more established industrially, their commercial costs will reduce. In addition, further research should focus on the identification of cheaper IL candidates.

Interestingly, the utility costs for the pervaporation system are the lowest, even though this technology is only the $3^{\text {rd }}$ most energy efficient. This can be attributed to the relatively low electrical energy requirements of $55.9 \mathrm{~kW}$, compared to $270.8 \mathrm{~kW}$ for IL extraction, which is significantly more expensive to supply than steam and cooling water. However, the total operating costs remain above those for distillation and IL extraction, presumably as a result of the high maintenance costs of the gas compressors. The lowest operating costs are achieved from the IL system, however this does not account for the degradation and loss of ionic liquid into the growth medium. In addition, the toxicological impacts of IL extraction on algae cultures have yet to be investigated, whereas the other three technologies would not be expected to effect the viability of the culture. 


\section{Conclusions}

The recovery of butanol from dilute growth cultures constitutes a major cost in the development of production systems based on genetically engineered cyanobacteria. By conducting extensive process modelling, we were able to provide a like-for-like comparison of the energy requirements of four of the most promising butanol separation technologies. In all cases, the break-even concentrations, at which the separation energy drops below the energy content of the fuel, are substantially higher than the butanol concentrations currently achieved in the literature. With a break-even concentration of $3.7 \mathrm{~g} \mathrm{~L}^{-1}$ ionic liquid extraction (ILE) is by far the most energy efficient separation technology, as it eliminates the heating of the entire cultivation broth. The pervaporation process appears to be limited by the low temperatures required to condense butanol from the low-pressure permeate, reducing the potential for heat integration and raising the energy requirements above the distillation base case. In contrast, gas stripping is significantly more energy intensive than all other technologies and therefore does not appear to offer any discernible advantages.

Despite the significant difference in energy requirements, the ILE process is only slightly cheaper to run than distillation and significantly more expensive to install, owing to the high costs of the ionic liquid. Even at $10 \mathrm{~g} \mathrm{~L}^{-1}$, the projected operating costs of $\$ 1.74 \mathrm{~kg}^{-1}$ (butanol) appear quite high compared to the value of the product. This suggests that the butanol concentrations required for economic operation are significantly higher than the calculated break-even concentrations, although costs could be reduced by changing the scale of the facility. In addition, the current work only considers the butanol product itself, whilst the process also yields significant amounts of waste biomass. Utilisation of this biomass could represent an additional product stream, reducing the costs associated with biofuel production.

It should also be noted that besides energy efficiency, the viability of the different separation systems also depends on other factors (e.g. environmental, safety, reliability) which have not been evaluated in this study. Future work should therefore consider the whole life-cycle perspectives of this process to provide an even more robust comparison. More detailed life 
cycle analysis of the whole excreted biofuel production system is currently under way as part of the Horizon 2020 'Photofuel' project.

\section{Declarations of interest:}

None.

\section{Acknowledgments}

This project has received funding from the European Union's Horizon 2020 research and innovation programme under grant agreement No 640720.

\section{APPENDIX A: Effect of butanol concentration on optimized model parameters}

Increasing the butanol concentration from $1 \mathrm{~g} \mathrm{~L}^{-1}$ to $10 \mathrm{~g} \mathrm{~L}^{-1}$ had a small impact on some of the optimised parameters for the four separation systems.

In the case of the distillation option, increasing the butanol concentration had a minimal impact on the MRR, whereas the DFMR had to be increased from 0.0065 to 0.018 , to maintain a sufficiently high butanol recovery from the column. At the same time, the optimal feed temperature, after energy integration, increased from $80^{\circ} \mathrm{C}$ to $90^{\circ} \mathrm{C}$.

For the gas stripping option, the optimal $1^{\text {st }}$ stage stripping ratio increased gradually from 0.05 at $1 \mathrm{~g} \mathrm{~L}^{-1}$ to 0.08 at $10 \mathrm{~g} \mathrm{~L}^{-1}$, whilst the optimal stripping temperature reduced from $86{ }^{\circ} \mathrm{C}$ to $83^{\circ} \mathrm{C}$.

Re-optimising the pervaporation system at higher butanol inlet concentrations resulted in a slight increase in the $2^{\text {nd }}$ stage stagecut from 0.13 to 0.17 , whilst the $1^{\text {st }}$ stage stagecut and pervaporation temperature remained unchanged at 0.03 and $90^{\circ} \mathrm{C}$, respectively. 
In the case of ionic liquid reduction, the $1^{\text {st }}$ stage ILFR reduced slightly from 0.6 to 0.5 , whilst the flash temperature reduced from $180^{\circ} \mathrm{C}$ to $165^{\circ} \mathrm{C}$, as the effect of recycling slightly higher butanol concentrations to the PBR becomes less important.

\section{References}

[1] P. Dürre, Biobutanol: An attractive biofuel, Biotechnol. J. 2 (2007) 1525-1534. doi:10.1002/biot.200700168.

[2] European Union, DIRECTIVE 2009/30, European Union, 2009.

[3] Renewable Fuels Association, Accelerating Industry Innovation - 2012 Ethanol Industry Outlook, 2012.

[4] S.Y. Lee, J.H. Park, S.H. Jang, L.K. Nielsen, J. Kim, K.S. Jung, Fermentative butanol production by clostridia, Biotechnol. Bioeng. $101 \quad$ (2008) 209-228. doi:10.1002/bit.22003.

[5] B. Ndaba, I. Chiyanzu, S. Marx, N-Butanol derived from biochemical and chemical routes: A review, Biotechnol. Reports. 8 (2015) 1-9. doi:10.1016/j.btre.2015.08.001.

[6] K. Karimi, M. Tabatabaei, I. Sárvári Horváth, R. Kumar, Recent trends in acetone, butanol, and ethanol (ABE) production, Biofuel Res. J. 2 (2015) 301-308. doi:10.18331/BRJ2015.2.4.4.

[7] E.I. Lan, J.C. Liao, Metabolic engineering of cyanobacteria for 1-butanol production from carbon dioxide, Metab. Eng. 13 (2011) 353-363. doi:10.1016/j.ymben.2011.04.004.

[8] E.I. Lan, J.C. Liao, ATP drives direct photosynthetic production of 1-butanol in cyanobacteria, Proc. Natl. Acad. Sci. $109 \quad$ (2012) 6018-6023. 
doi:10.1073/pnas.1200074109.

[9] E.I. Lan, S.Y. Ro, J.C. Liao, Oxygen-tolerant coenzyme A-acylating aldehyde dehydrogenase facilitates efficient photosynthetic n-butanol biosynthesis in cyanobacteria, Energy Environ. Sci. 6 (2013) 2672. doi:10.1039/c3ee41405a.

[10] J. Anfelt, Metabolic engineering strategies to increase $n$-butanol production from cyanobacteria, 2016.

[11] J. Anfelt, B. Hallström, J. Nielsen, M. Uhlén, E.P. Hudson, Using transcriptomics to improve butanol tolerance of Synechocystis sp. Strain PCC 6803, Appl. Environ. Microbiol. 79 (2013) 7419-7427. doi:10.1128/AEM.02694-13.

[12] L. Chen, L. Wu, J. Wang, W. Zhang, Butanol tolerance regulated by a two-component response regulator SIr1037 in photosynthetic Synechocystis sp. PCC 6803, Biotechnol. Biofuels. 7 (2014) 89. doi:10.1186/1754-6834-7-89.

[13] X. Niu, Y. Zhu, G. Pei, L. Wu, L. Chen, W. Zhang, Elucidating butanol tolerance mediated by a response regulator SII0039 in Synechocystis sp. PCC 6803 using a metabolomic approach, Appl. Microbiol. Biotechnol. 99 (2015) 1845-1857. doi:10.1007/s00253-015-6374-y.

[14] Y. Wang, M. Shi, X. Niu, X. Zhang, L. Gao, L. Chen, J. Wang, W. Zhang, Metabolomic basis of laboratory evolution of butanol tolerance in photosynthetic Synechocystis sp. PCC 6803, Microb. Cell Fact. 13 (2014) 151. doi:10.1186/s12934-014-0151-y.

[15] W.L. Luyben, Control of the Heterogeneous Azeotropic n -Butanol/Water Distillation System, Energy \& Fuels. 22 (2008) 4249-4258. doi:10.1021/ef8004064.

[16] L.M. Vane, F.R. Alvarez, Hybrid vapor stripping-vapor permeation process for recovery and dehydration of 1-butanol and acetone/butanol/ethanol from dilute aqueous solutions. Part 1. Process Simulations, J. Chem. Technol. Biotechnol. 88 (2013) 14361447. doi:10.1002/jctb.4087. 
[17] C. Xue, J. Zhao, L. Chen, S.T. Yang, F. Bai, Recent advances and state-of-the-art strategies in strain and process engineering for biobutanol production by Clostridium $\begin{array}{llll}\text { acetobutylicum, } & \text { Biotechnol. } & \text { Adv. } & 35 \quad \text { (2017) }\end{array}$ doi:10.1016/j.biotechadv.2017.01.007.

[18] A. Sharif Rohani, P. Mehrani, J. Thibault, Comparison of in-situ recovery methods of gas stripping, pervaporation, and vacuum separation by multi-objective optimization for producing biobutanol via fermentation process, Can. J. Chem. Eng. 93 (2015) 986-997. doi:10.1002/cjce.22186.

[19] D. Zhang, P. Dechatiwongse, E.A. del Rio-Chanona, G.C. Maitland, K. Hellgardt, V.S. Vassiliadis, Modelling of light and temperature influences on cyanobacterial growth and biohydrogen production, Algal Res. 9 (2015) 263-274. doi:10.1016/j.algal.2015.03.015.

[20] T. Zavřel, M.A. Sinetova, D. Búzová, P. Literáková, J. Červený, Characterization of a model cyanobacterium Synechocystis sp: PCC 6803 autotrophic growth in a flat-panel photobioreactor, Eng. Life Sci. 15 (2015) 122-132. doi:10.1002/elsc.201300165.

[21] M. Singh, R. Shukla, K. Das, Harvesting of Microalgal Biomass, Biotechnol. Appl. Microalgae Biodiesel Value-Added Prod. (2013) 77-88. doi:10.1007/978-3-319-123349_5.

[22] R. Rautenbach, C. Herion, M. Franke, A.-F.A. Asfour, A. Bemquerer-Costa, E. Bo, Investigation of mass transport in asymmetric pervaporation membranes, J. Memb. Sci. 36 (1988) 445-462. doi:10.1016/0376-7388(88)80035-8.

[23] S. Claes, P. Vandezande, S. Mullens, K. De Sitter, R. Peeters, M.K. Van Bael, Preparation and benchmarking of thin film supported PTMSP-silica pervaporation membranes, J. Memb. Sci. 389 (2012) 265-271. doi:10.1016/j.memsci.2011.10.035.

[24] K.S. Houston, D.H. Weinkauf, F.F. Stewart, Gas transport characteristics of plasma treated poly(dimethylsiloxane) and polyphosphazene membrane materials, J. Memb. 
Sci. 205 (2002) 103-112. doi:10.1016/S0376-7388(02)00068-6.

[25] A. Kubiczek, W. Kamiński, A. Górak, Modeling of single- and multi-stage extraction in the system of water, acetone, butanol, ethanol and ionic liquid, Fluid Phase Equilib. 425 (2016) 365-373. doi:10.1016/j.fluid.2016.05.023.

[26] J.-G. Li, Y.-F. Hu, S. Ling, J.-Z. Zhang, Physicochemical Properties of [C 6 mim][PF 6 ] and [C 6 mim][(C 2 F 5 ) 3 PF 3 ] lonic Liquids, J. Chem. Eng. Data. 56 (2011) 30683072. doi:10.1021/je200073x.

[27] D. Zhang, M. Wan, E.A. del Rio-Chanona, J. Huang, W. Wang, Y. Li, V.S. Vassiliadis, Dynamic modelling of Haematococcus pluvialis photoinduction for astaxanthin production in both attached and suspended photobioreactors, Algal Res. 13 (2016) 69_ 78. doi:10.1016/j.algal.2015.11.019.

[28] C. Posten, Design principles of photo-bioreactors for cultivation of microalgae, Eng. Life Sci. 9 (2009) 165-177. doi:10.1002/elsc.200900003.

[29] D. Zhang, P. Dechatiwongse, K. Hellgardt, Modelling light transmission, cyanobacterial growth kinetics and fluid dynamics in a laboratory scale multiphase photo-bioreactor for biological hydrogen production, Algal Res. 8 (2015) 99-107. doi:10.1016/j.algal.2015.01.006.

[30] I. Harun, E.A. Del Rio-Chanona, J.L. Wagner, K.J. Lauersen, D. Zhang, K. Hellgardt, Photocatalytic Production of Bisabolene from Green Microalgae Mutant: Process Analysis and Kinetic Modeling, Ind. Eng. Chem. Res. 57 (2018) 10336-10344. doi:10.1021/acs.iecr.8b02509. 